\title{
Influência de diferentes concentrações dos fitorreguladores ácido 6-benzilaminopurina e ácido naftalenoacético na propagação vegetativa de Malva sylvestris L.
}

\begin{abstract}
FILTER, M. ${ }^{\dagger} ;$ FREITAS, E.M.DE ${ }^{1}$; PÉRICO, E. ${ }^{2}$
†In memorian. Bióloga pelo Curso de Ciências Biológicas; trabalho realizado quando foi Bolsista de Iniciação Científica no Laboratório de Propagação de Plantas do Centro Universitário UNIVATES; Centro Universitário UNIVATES, Programa de Pós-Graduação em Biotecnologia (PPGBiotec), Curso de Ciências Biológicas, Laboratório de Propagação de Plantas, Museu de Ciências Naturais. Avenida Avelino Tallini, 171, Lajeado/RS, 95900-000. Autor para correspondência: elicauf@univates.br; ${ }^{2}$ Centro Universitário UNIVATES, Programa de Pós-Graduação em Ambiente e Desenvolvimento (PPGAD), Curso de Ciências Biológicas, Museu de Ciências Naturais.
\end{abstract}

RESUMO: Malva sylvestris L. (família Malvaceae), conhecida como malva, é uma espécie medicinal nativa da Europa, cultivada no sul do Brasil. A espécie tem propriedade adstringente, suaviza a irritação dos tecidos e reduz inflamações, entre outras características e atributos medicinais. O estudo teve como objetivo verificar a eficiência dos hormônios ANA (ácido naftalenoacético) e BAP (ácido 6-Benzilaminopurina) na propagação vegetativa a partir do estabelecimento in vitro de segmentos nodais. Segmentos nodais obtidos de plantas matrizes mantidas em casa de vegetação foram submetidos à desinfestação e inoculados em meio MS (Murashige e Skoog) com diferentes concentrações e combinações de ANA (ácido naftalenoacético) e BAP (ácido 6-Benzilaminopurina) totalizando oito tratamentos com 60 repetições cada. Os explantes foram mantidos em sala de crescimento e, ao completar sete dias, as plântulas obtidas foram retiradas e avaliadas quanto ao número de folhas, altura total $(\mathrm{cm})$ e massa fresca $(\mathrm{g})$. As plântulas foram fixadas em substrato "Big bio" e transferidas para casa de vegetação com nebulização. Os dados obtidos foram submetidos à Análise de Variância, seguido pelo Teste de Tukey. As plântulas obtidas em meio MS acrescido de $2,0 \mathrm{mg} /$ $\mathrm{L}^{-1}$ de BAP e de $0,5 \mathrm{mg} / \mathrm{L}^{-1}$ de ANA foram as que apresentaram maior média nas três variáveis avaliadas, sendo então o mais indicado para a produção de mudas. Em 10 dias foi observado o enraizamento de todas as plântulas transferidas para casa de vegetação. A aclimatização e o enraizamento ex vitro ocorrem em uma única etapa sem a necessidade da utilização de enraizadores. A técnica desenvolvida demonstra a possibilidade de produção de mudas com custos reduzidos, em larga escala, e com a garantia de fornecer mudas aptas para o cultivo em apenas 17 dias.

Palavras chave: cultivo in vitro, espécie medicinal, reguladores de crescimento, enraizamento, aclimatização.

ABSTRACT: Effect of different BAP and NAA concentration on microprapagation of Malva (Malva sylvestris L.). Effect of different BAP and NAA concentrations on malva (Malva sylvestris L.) micropropagation. Malva sylvestris L. (Malvaceae family), known as mallow, is a medicinal species native toEurope, and it is grown in southern Brazil. It has astringent properties and can sooth tissue irritation and reduce inflammations among other medicinal characteristics. The study aimed to verify the efficiency of the hormones NAA (naphthalene acetic acid) and BAP (6-Benzilaminopurine acid) in propagating the species from establishing in vitro nodal segments. Nodal segments obtained from mother plants kept in greenhouses were disinfected and inoculated in MS medium with different concentrations and combinations of BAP and NAA, amounting to 8 processes with 60 repetitions each. The explants were kept in growth rooms, and after seven days the resulting seedling were removed and assessed regarding the number of leaves, total height $(\mathrm{cm})$ and fresh mass $(\mathrm{g})$. Subsequently, the seedling were fixed on the substrate "Big bio" and transferred to greenhouses with nebulization. The data obtained was subjected toVariance Analysis, followed by the Tukey's test. In 10 days,rooting

Recebido para publicação em 15/12/2011

Aceito para publicação em 18/06/2013

Rev. Bras. PI. Med., Campinas, v.16, n.1, p.47-53, 2014. 
could be observed in all the plantules transferred to the greenhouse. The plantules obtained in MS medium thatreceived $2.0 \mathrm{mg} / \mathrm{L}^{-1} \mathrm{BAP}$ and $0.5 \mathrm{mg} / \mathrm{L}^{-1} \mathrm{NAA}$ were the ones that presented the highest average in the three variables assessed, therefore the most recommended to producing seedlings of this species. The ex vitro acclimatization and rooting occur in a single phase without the need of root promoters. The technique developed shows that it is possible to produce seedlings of this species at reduced costs, in large scale and with the guarantee to supply seedlings that can be planted in only 17 days.

Keywords: in vitro culture, medicinal species, growth regulators, rooting, acclimatization.

\section{INTRODUÇÃO}

O uso de plantas medicinais, tanto para o tratamento e cura, como para a prevenção de doenças é uma das formas mais antigas de prática medicinal pela humanidade (Veiga Jr. et al., 2005). Elas representam fator de grande importância para a manutenção das condições de saúde, além de fazer parte da cultura dos povos, sendo parte de um saber utilizado e difundido pelas populações ao longo de várias gerações (Tomazzoni, et al., 2006). Essa cultura medicinal tem despertado cada vez mais o interesse de pesquisadores em estudos envolvendo áreas multidiciplinares como, por exemplo, a botânica, a farmacologia e a fitoquímica, que juntas enriquecem os conhecimentos sobre a inesgotável fonte medicinal natural da flora mundial (Maciel et al., 2002). Segundo Bosembecker (2001), mais de $40 \%$ dos medicamentos farmacêuticos produzidos no Brasil têm princípios ativos retirados de plantas, com efeitos colaterais menores aos pacientes e com baixo custo. Consequentemente, é cada vez maior o número de centros de pesquisas dedicados à fitoterapia nas universidades brasileiras.

Apesar disso, muitas espécies, frequentemente utilizadas por populações locais, ainda não foram estudadas e não tem identificados ou seus princípios ativos, não sendo validadas como fitoterápicos (Berg, 1993). Com a divulgação da Relação Nacional de Plantas Medicinais de Interesse ao Sistema Único de Saúde (RENISUS), realizada pelo Ministério da Saúde, contendo 71 espécies vegetais medicinais (BRASIL, 2009), esse quadro pode ser modificado, tendo em vista que a finalidade da relação é orientar estudos e pesquisas com essas espécies para subsidiar a elaboração da lista de plantas medicinais e fitoterápicos a serem disponibilizados para uso pela população.

Além dos objetivos de aumentar a disponibilidade de plantas medicinais como fitoterápicos para a população e de promover o desenvolvimento de tecnologias e inovações em plantas medicinais e fitoterápicos nas diversas fases da cadeia produtiva, o Programa Nacional de Plantas Medicinais e Fitoterápicos (PNPMF) tem, dentre outras diretrizes, a de promover a inclusão da agricultura familiar nas cadeias e nos arranjos produtivos das plantas medicinais, insumos e fitoterápicos e ainda, estimular a produção de fitoterápicos em escala industrial (BRASIL, 2006).

É neste contexto que a propagação vegetativa, em especial o cultivo in vitro de plantas medicinais, aparece como alternativa a ser adotada, pois permite a produção comercial de mudas homogêneas e de qualidade, a conservação do germoplasma e auxilia na seleção e no melhoramento de genótipos com potencial para uso pela indústria farmacêutica (Rao \& Ravishankar, 2002). O sucesso da propagação vegetativa pode ser favorecida pela utilização de reguladores de crescimento adicionados aos meios nutritivos em que os explantes são submetidos quando em cultivo in vitro, pois estes suprem deficiências dos teores endógenos de fitorreguladores nos explantes (George \& Sherrington, 1984). Dentre estes, está a citocinina ácido 6-Benzilaminopurina (BAP) e a auxina ácido naftalenoacético (ANA), ambas muito utilizadas, sendo a concentração um dos fatores que mais influenciam o processo de desenvolvimento in vitro (Mantovani et al., 2001).

Com o intuito de contribuir para o avanço das pesquisas e de estimular a implantação de atividades econômicas com plantas medicinais, foi selecionada a espécie Malva sylvestris L. (malva) dentre as que compõem a RENISUS (BRASIL, 2009). Trata-se de uma espécie nativa da Europa, pertencente à Família Malvaceae, de hábito herbáceo, ereta ou decumbente, com ciclo de vida bianual ou perene (Boorhem et al., 1999, Alzugaray \& Alzugaray 1996). Os autores citam que a espécie é considerada erva mucilaginosa e levemente adstringente, citada na literatura etnofarmacológica como medicação capaz de suavizar a irritação dos tecidos e reduzir inflamações, especialmente da pele, da boca e da garganta. Diante dessas propriedades, o presente estudo teve como objetivo, verificar a eficiência dos hormônos ANA (ácido naftalenoacético) e BAP (ácido 6-Benzilaminopurina)

Rev. Bras. PI. Med., Campinas, v.16, n.1, p.47-53, 2014. 
na propagação vegetativa de Malva sylvestris a partir do estabelecimento in vitro de segmentos nodais.

\section{MATERIAL E MÉTODO}

O experimento foi conduzido no Laboratório de Propagação de Plantas e em casa de vegetação do Centro Universitário UNIVATES. Plantas matrizes de Malva sylvestris foram mantidas em casa de vegetação e submetidas à aplicação diária, por cinco dias, do fungicida Orthocide. Segmentos nodais de um centímetro foram obtidos de plantas matrizes e submersos em recipientes com água corrente contendo uma gota de detergente neutro durante 10 minutos. Em seguida, em capela de fluxo laminar horizontal, foram imersos em álcool $70 \%$ por 60 segundos, seguindo para solução de hipoclorito de sódio comercial $(80 \%)$ com uma gota de detergente neutro e $0,5 \mathrm{mg} \cdot \mathrm{L}^{-1}$ do fungicida Orthocide por 20 minutos. Os explantes passaram por cinco lavagens em água destilada autoclavada.

O meio de cultura utilizado foi o MS (Murashige \& Skoog, 1962) solidificado com 7,0 g. $\mathrm{L}^{-1}$ de ágar e $\mathrm{pH}$ ajustado em 5,8 antes de ser autoclavado a $121^{\circ} \mathrm{C}$ e $1,2 \mathrm{~atm}$ durante 20 minutos. Ao meio de cultura foram adicionadas diferentes concentrações dos reguladores de crescimento BAP e ANA, constituindo oito tratamentos: $\mathrm{MSI}(0,0$ mg. $\mathrm{L}^{-1}=$ controle $) ; \mathrm{MSII}\left(0,5 \mathrm{mg} \cdot \mathrm{L}^{-1}\right.$ de ANA $) ; \mathrm{MSIII}$ (1,0 mg. $\mathrm{L}^{-1}$ de BAP); MSIV (1,0 mg. $\mathrm{L}^{-1}$ de BAP e 0,5 mg. $\mathrm{L}^{-1}$ de ANA); MSV (2,0 mg. $\mathrm{L}^{-1}$ de BAP); MSVI (2,0 mg. $\mathrm{L}^{-1}$ de BAP e 0,5 mg. $\mathrm{L}^{-1}$ de ANA); MSVII (4,0 mg. $\mathrm{L}^{-1}$ de BAP) e MSVIII $\left(4,0 \mathrm{mg} \cdot \mathrm{L}^{-1}\right.$ de BAP e $0,5 \mathrm{mg} \cdot \mathrm{L}^{-1}$ de ANA). O delineamento experimental foi inteiramente casualizado, com oito tratamentos, cada um com 60 explantes.

Em capela de fluxo laminar, os explantes foram inoculados individualmente em tubos de ensaio contendo $25 \mathrm{~mL}$ do meio de cultura e mantidos em sala de crescimento com temperatura de $25 \pm 3^{\circ} \mathrm{C}$ e fotoperíodo de 16 horas/luz. O período de cultivo in vitro foi planejado inicialmente para 30 dias. No entanto, em razão do acentuado crescimento apresentado pelas plântulas, estas foram removidas dos tubos ao completar apenas sete dias, sendo então avaliadas quanto às variáveis: (1) altura total, (2) número de folhas, (3) presença ou ausência de raízes e (4) massa fresca. Esta última foi verificada através da diferença entre a massa obtida pela pesagem dos explantes antes da inoculação e das plântulas obtidas após o período de inoculação, utilizando-se de balança digital analítica com precisão de $0,0001 \mathrm{~g}$. Para a obtenção da massa fresca após o período de cultivo in vitro, as plântulas foram lavadas e secas com o uso de papel toalha, conforme proposto por Nakagawa (1994).

A normalidade dos dados foi testada pelo teste de D’Agostino (Zar, 1999). Em razão dos dados não seguirem distribuição normal foram transformados e normalizados utilizando-se a logaritmização (LN $(X+1))$. Os dados foram testados por Análise de Variância (ANOVA) e aplicado o Teste de Tukey (Zar, 1999) nos casos de haver diferença na ANOVA.

As plântulas obtidas nos tratamentos in vitro foram fixadas em substrato "Big Bio" sem a utilização de fitorreguladores, e mantidas em casa de vegetação com umidade e temperatura médias de $60 \%$ e $27^{\circ} \mathrm{C}$.

\section{RESULTADOS E DISCUSSÃO}

O índice de contaminação por fungos e bactérias, considerando as 480 inoculações, foi de apenas $2 \%$, confirmando a eficiência do método de desinfestação adotado.

Em sete dias de cultivo in vitro ocorreu a formação de um broto a partir da gema presente nos segmentos nodais de todos os tratamentos, apresentando, inclusive, acentuado crescimento, tornando necessária a remoção das plântulas dos tubos de ensaio antes do período previamente planejado (30 dias). No entanto, nenhum segmento apresentou raízes, fato causado, provavelmente pelo curto período de tempo de cultivo in vitro, tendo em vista que todas as plântulas obtidas, quando submetidas ao processo de aclimatização em casa de vegetação, apresentaram raízes em dez dias de cultivo sem a utilização de hormônio enraizador. Conforme Rohr \& Hanus (1987), as respostas às auxinas não são universais, pois certas espécies, nem mesmo na presença de auxinas, conseguem enraizar, enquanto algumas até dispensam o uso de hormônios enraizadores. Considerando o período de cultivo in vitro e a aclimatização (com enraizamento), em apenas 17 dias foi possível obter mudas de $M$. sylvestris em grande quantidade e de qualidade.

A análise estatística das variáveis altura (cm), número de folhas e massa fresca $(\mathrm{g})$, obtidas aos sete dias de cultivo in vitro, mostrou que no tratamento MSVI (2,0 mg. $\mathrm{L}^{-1}$ de BAP e 0,5 mg. $\mathrm{L}^{-1}$ de ANA) as plântulas apresentaram melhor desenvolvimento. Neste tratamento a altura média atingida pelas brotações $(3,71 \mathrm{~cm})$, o número de folhas formadas $(2,25)$ e o acréscimo médio de massa fresca $(0,38 \mathrm{~g})$ foi maior quando comparado aos demais tratamentos (Tabela 1; Figura 1).

A variável massa fresca foi utilizada para medir o crescimento celular (biomassa) durante o período de cultivo in vitro. Considerando que a massa fresca média dos explantes quando inoculados foi de 0,04 g, o tratamento MSII apresentou o menor incremento de biomassa $(0,19 \mathrm{~g})$, sendo seguido por MSI (controle), diferindo pouco da média inicial de massa fresca, indicando baixo crescimento celular.

Rev. Bras. PI. Med., Campinas, v.16, n.1, p.47-53, 2014. 
De forma inversa, o tratamento MSVI apresentou maior acréscimo de massa fresca média $(0,38 \mathrm{~g})$, diferindo significativamente de todos os demais tratamentos que, por sua vez, não diferiram entre si. Ao considerar a variável altura total, a diferença entre MSVI só não foi significativa em relação ao tratamento MSIV $\left(1,0 \mathrm{mg} \cdot \mathrm{L}^{-1}\right.$ de BAP e 0,5 mg. $\mathrm{L}^{-1}$ de ANA), pois este apresentou a segunda maior média de altura $(3,19 \mathrm{~cm})$. Quanto ao número de folhas, MSVI diferiu significativamente de MSI, MSII e MSV, cujas médias foram muito inferiores $(1,60$, $1,78,1,43$, respectivamente).

As médias do número de folhas, altura e massa fresca foram baixas no tratamento controle (MSI), dados que corroboram com Abreu et al. (2003), pois ao trabalhar com a propagação de Cissus sicyoides L., constatou que a presença de reguladores de crescimento no meio de cultura influenciou de modo significativo os resultados. Em MSII, o desenvolvimento da plântula também foi reduzido e não houve enraizamento, apesar de ser esta uma das funções do hormônio ANA, utilizada no tratamento. Em MSIII, quando a concentração de BAP usada foi de $1,0 \mathrm{mg} \cdot \mathrm{L}^{-1}$, as médias das variáveis foram um pouco maiores e se elevaram ainda mais em MSV, confirmando que o BAP, segundo Zaerr \& Mapes (1985), é a citocina mais eficaz para a multiplicação das partes aéreas da maioria das espécies.

No entanto, quando a concentração de BAP passa a ser 2,0 mg. $\mathrm{L}^{-1}$ acrescida de ANA, as médias são ainda maiores, mostrando que a presença de hormônios ANA e BAP, de forma associada, é essencial para a micropropagação da espécie a partir de segmentos nodais, confirmando que a suplementação de auxina/citocina é necessária na regulação da divisão celular, no alongamento celular, na diferenciação celular e formação de órgãos
(Dodds \& Roberts, 1999). Macedo et al. (2003) também constataram que pequenas concentrações de BAP conjugados com ANA proporcionaram maior massa fresca de plântulas de Ananas comosus (L.) Merr. A conjugação dos hormônios nem sempre é favorável para as espécies, tendo em vista que em plântulas de Ocimum basilicum L., a adição de 2,0 $\mathrm{mg} / \mathrm{L}^{-1}$ de BAP ao meio promoveu melhor resposta organogênica, sendo desnecessário o uso de ANA (Rebouças, 2009). Tavano et al. (2009) constatou que plântulas de Matricaria recutita L. apresentaram maior taxa de multiplicação na presença de BAP em concentrações abaixo de $1,0 \mathrm{mg} / \mathrm{L}^{-1}$, enquanto que em diferentes concentrações com ANA houve formação de calos.

No presente estudo, ao dobrar a dosagem do BAP $\left(4,0 \mathrm{mg} \cdot \mathrm{L}^{-1}\right)$, nos tratamentos MSVII e MSVIII, as médias das variáveis avaliadas volta a reduzir (Tabela 1), indicando a possibilidade de que a concentração testada começa a exibir efeitos inibitórios, como se agissem com toxicidade na planta. Elevadas concentrações de BAP ocasionaram diminuição da massa fresca de Sinningia speciosa Lodd. Hiern, possivelmente devido à emissão de grande número de brotações de menor tamanho (Silva, 2001).

A indução e a expressão das possíveis respostas morfogenéticas em cultura de células, tecidos e órgãos in vitro são dependentes de fatores externos, químicos e físicos, como meio de cultura e reguladores vegetais. Também dependem das condições de cultivo, como temperatura e luminosidade, e de fatores inerentes ao material vegetal, tais como genéticos e fisiológicos da plantamãe doadora do explante (Grattapaglia \& Machado, 1990). A disponibilidade e interação de auxinas e citocinas no meio de cultura levam ao crescimento e morfogênese in vitro, tendo importante influência

TABELA 1. Média das variáveis altura, número de folhas e massa fresca, obtidas nas plântulas de Malva sylvestris durante o cultivo in vitro nos oito tratamentos (MSI $=0 \mathrm{mg} \cdot \mathrm{L}^{-1} ; \mathrm{MSI}=0,5 \mathrm{mg} \cdot \mathrm{L}^{-1}$ de ANA; MSIII=1,0 $\mathrm{mg} \cdot \mathrm{L}^{-1}$ de BAP; $M S I V=1,0 \mathrm{mg} \cdot \mathrm{L}^{-1}$ de BAP e 0,5 mg. $\mathrm{L}^{-1}$ de ANA; $M S V=2,0 \mathrm{mg} \cdot \mathrm{L}^{-1}$ de BAP; $M S V I=2,0 \mathrm{mg} \cdot \mathrm{L}^{-1}$

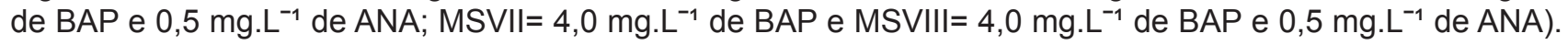
Valores médios que apresentam a mesma letra sobescrita, não diferem significativamente entre si.

\begin{tabular}{cccc}
\hline Tratamentos & $\begin{array}{c}\text { Altura média } \\
(\mathbf{c m})\end{array}$ & $\begin{array}{c}\text { Número médio } \\
\text { de folhas }\end{array}$ & $\begin{array}{c}\text { Massa } \\
\text { fresca média }(\mathrm{g})\end{array}$ \\
\hline MS I & $2,60^{\mathrm{c}}$ & $1,60^{\mathrm{bcd}}$ & $0,22^{\mathrm{a}}$ \\
MS II & $2,53^{\mathrm{c}}$ & $1,78^{\mathrm{bcd}}$ & $0,19^{\mathrm{a}}$ \\
MS III & $2,70^{\mathrm{b}}$ & $1,87^{\mathrm{abcd}}$ & $0,24^{\mathrm{a}}$ \\
MS IV & $3,19^{\mathrm{ab}}$ & $1,95^{\mathrm{abcd}}$ & $0,23^{\mathrm{a}}$ \\
MS V & $3,01^{\mathrm{b}}$ & $1,43^{\text {bcd }}$ & $0,29^{\mathrm{a}}$ \\
MSVI & $3,71^{\mathrm{a}}$ & $2,25^{\mathrm{abcd}}$ & $0,38^{\mathrm{b}}$ \\
MS VII & $2,60^{\mathrm{b}}$ & $2,07^{\mathrm{abcd}}$ & $0,24^{\mathrm{a}}$ \\
MS VIII & $2,63^{\mathrm{b}}$ & $2,00^{\text {abcd }}$ & $0,25^{\mathrm{a}}$ \\
\hline
\end{tabular}

Rev. Bras. PI. Med., Campinas, v.16, n.1, p.47-53, 2014. 
FIGURA 1. Média e desvio padrão das variáveis altura, número de folhas e massa fresca nos oito meios testados. $\square$ Altura $\longleftarrow N^{\circ}$ folhas $\longrightarrow$ Massa fresca

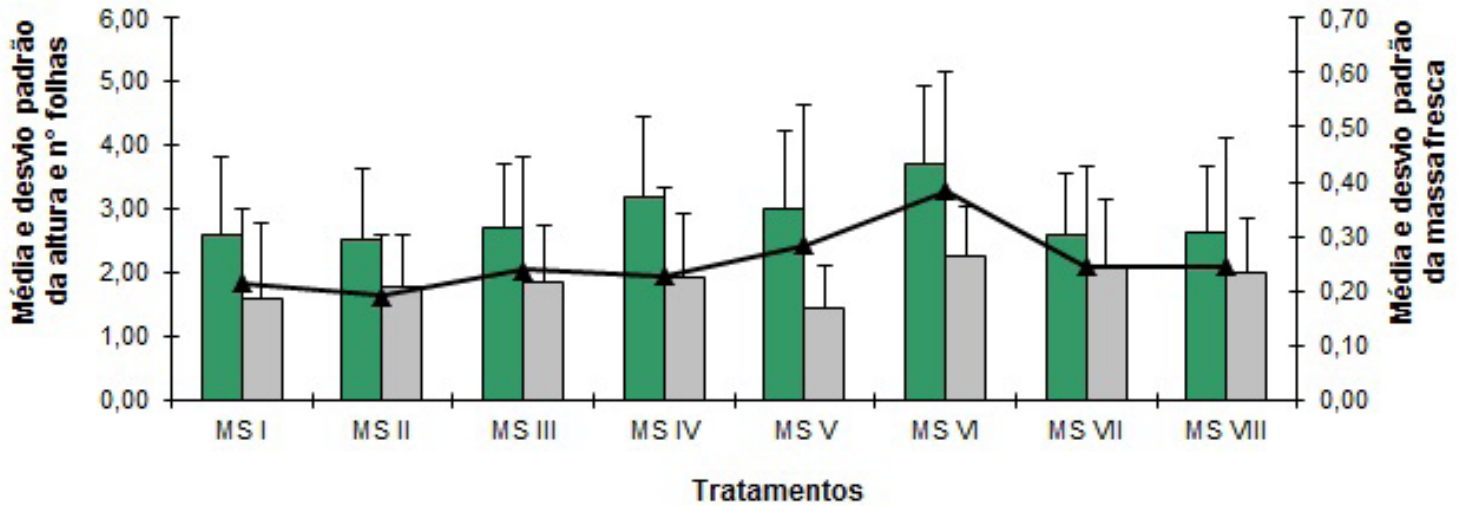

na formação das raízes, parte aérea e calo em cultura de tecidos. O efeito fisiológico depende da concentração de cada regulador no meio, sendo que cada parte da planta tem uma resposta diferente às alterações nas concentrações de auxinas e citocinas (Pozo et al. 2005).

Conforme a espécie e os objetivos do estudo, a sequência e o número de fases do processo de micropropagação podem ser alterados, conforme realizado no presente estudo. Como não houve enraizamento in vitro e as plântulas (Figura 2A) apresentavam tamanho que impedia a continuidade do cultivo nessas condições, as plântulas foram transferidas para bandejas plásticas com substrato "Big bio" e mantidas em casa de vegetação para aclimatização e enraizamento. A vantagem nesse procedimento é que evita a manipulação de plantas com raiz nua além da redução no período de produção no laboratório, economizando uma fase de desenvolvimento de pesquisa. Wendling \& Dutra (2010) ressaltam que o enraizamento ex vitro proporciona redução de custos de mão de obra e infraestrutura, economizando espaço na sala de crescimento, energia elétrica e meio de cultura sem a necessidade de aplicação de fitorreguladores. Além disso, o sistema radicular é mais completo e funcional, apresentando maior número de raízes secundárias. Além dessas vantagens, o sistema radicular quando formado no período de cultivo in vitro é pouco ramificado, quebradiço e isento de pelos radiculares, com raízes pouco funcionais na absorção de água e nutrientes (Hoffmann et al., 2001).

Em sete dias as plântulas já apresentavam sinais de estarem aclimatizadas (Figura 2B), sendo esta uma das fases mais críticas da micropropagação de plantas, pois requer atenção e cuidados devido à fragilidade das plântulas, já que apresentam perda de água por evapotranspiração e, segundo Hararika (2003), um número expressivo de indivíduos micropropagados não sobrevive quando transferidos das condições in vitro para ambiente de casa de vegetação ou campo. Aos 10 dias em casa de vegetação, todas as plântulas
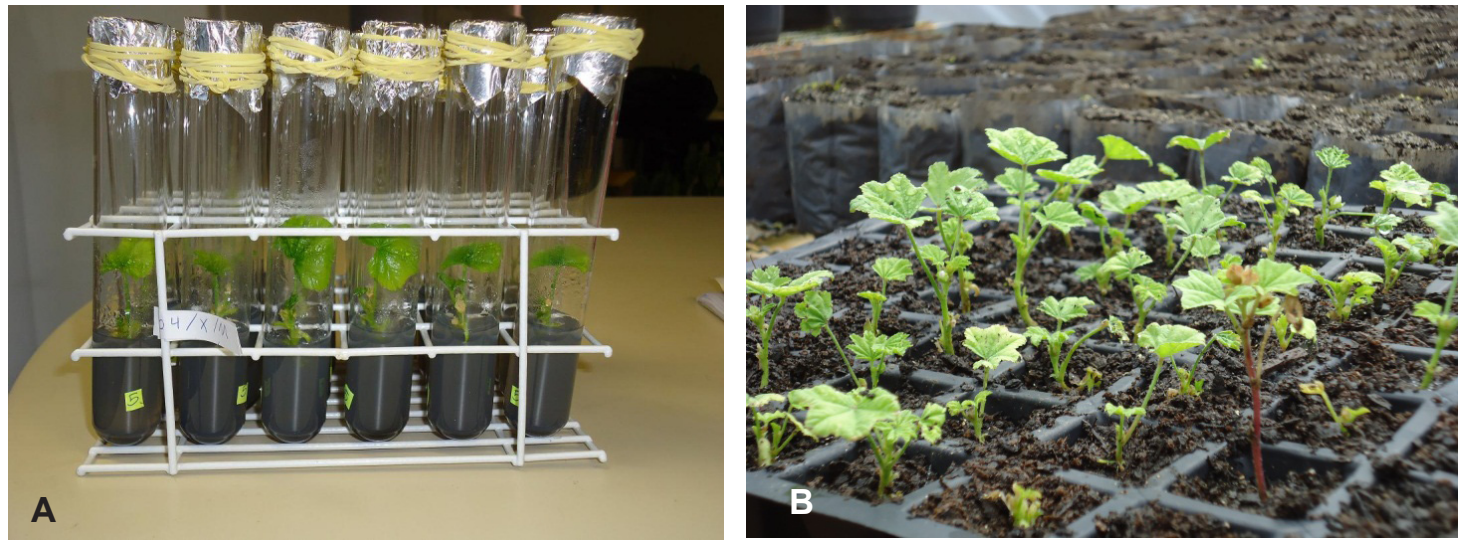

FIGURA 2. A. Plântulas aos seis dias de cultivo in vitro em meio MS V. B. Plântulas com sete dias de aclimatização em casa de vegetação.

Rev. Bras. Pl. Med., Campinas, v.16, n.1, p.47-53, 2014. 
estavam enraizadas. Acredita-se que a formação de raízes, paralela ao processo de aclimatização, tenha beneficiado a produção de mudas da espécie, em grande quantidade e em menor período de tempo que, somando-se o período de cultivo in vitro, foi de apenas 17 dias.

\section{CONCLUSÃO}

A produção de mudas pela técnica de cultivo in vitro de Malva sylvestris é viável com ou sem o uso de reguladores de crescimento, no entanto, o tratamento constituído pelo meio MS (MS VI), acrescido com 2,0 mg. $\mathrm{L}^{-1}$ de BAP e 0,5 $\mathrm{mg} \cdot \mathrm{L}^{-1}$ de ANA, apresentou as melhores médias para altura, número de folhas e de massa fresca, sendo o mais indicado para a propagação da espécie. A aclimatização e o enraizamento ex vitro da espécie podem ser realizados em uma única etapa, pelo período de 10 dias, com sucesso, sendo desnecessária a aplicação de enraizadores. Em 17 dias após a inoculação, as plantas estão aptas para o plantio em campo.

\section{AGRADECIMENTOS}

Aos colegas do Laboratório de Propagação de Plantas do Centro Universitário UNIVATES pelo auxílio em todas as etapas do trabalho. Ao Centro Universitário UNIVATES, à Prefeitura Municipal de Lajeado, ao Ministério da Ciência, Tecnologia e Inovação e à Secretaria da Ciência, Inovação e Desenvolvimento Tecnológico do Rio Grande do Sul pelo financiamento da pesquisa.

\section{REFERÊNCIA}

ABREU, I.N. et al. Propagação in vivo e in vitro de Cissus sicyoides, uma planta medicinal. Acta Amazonica, v. 33, n.1, p.1-7, 2003.

ALZUGARAY, D.; ALZUGARAY, C. Plantas que curam. v.1. São Paulo: Ed. Três, 1996. 260p.

BERG, M. E. Plantas Medicinais na Amazônia: contribuição ao seu conhecimento sistemático, Pará. Belém: Museu Paraense Emílio Goeldi, 1993. 206p.

BOORHEM, R.L. Segredos e virtudes das plantas medicinais. Rio de Janeiro: Reader's Digest Brasil Ltda., 1999. 416p.

BOSEMBECKER, V.K. Efeitos de substâncias de crescimento na micropropagação e morfogênese em camomila romana (Anthemis nobilis L.). 2001. 80 f. Dissertação (Mestrado em Fisiologia Vegetal) Universidade Federal de Pelotas, Pelotas, 2001.

BRASIL, Departamento de Assistência Farmacêutica e Insumos Estratégicos, Secretaria de Ciência, Tecnologia e Insumos Estratégicos, Ministério da Saúde. RENISUS - Relação Nacional de Plantas Medicinais de Interesse ao SUS. 2009. Brasília-DF. Disponível em: <http://portal. saude.gov.br/portal/ arquivos/pdf/ RENISUS.pdf>. Acesso em: 18 nov. 2011.

Ministério da Saúde. Política Nacional de Plantas Medicinais e Fitoterápicos. Brasília-DF, 2006. Disponível em: <http://bvsms.saude.gov.br/ bvs/publicacoes/ politica_nacional_fitoterapicos.pdf>. Acesso em: 18 nov. 2011.

DODDS, J.H.; ROBERTS, L.W. Experiments in plant tissue culture. Cambridge: Cambridge University Press, 1999. 256p.

GEORGE, E.F.; SHERRINGTON, P.D. Plant propagation by tissue culture: handbook and directory of commercial laboratories. Basingstoke, England: Eastern Press,1984. 709p.

GRATTAPAGLIA, D.; MACHADO, M.A. Micropropagação. In: TORRES, A.C., CALDAS, L.S. (Eds.). Técnicas e aplicações da cultura de tecidos em plantas. Brasília: Embrapa CNPH, 1990. p.99-169.

HARARIKA, B. N. Acclimatization of tissue-cultured plants. Current Science, Stanford, v. 85, n. 12, p. 1704-1712, 2003.

HOFFMANN, A.; PASQUAL, M.; CHALFUN, N. N. J.; FRÁGUAS, C. B. Efeito de substratos na aclimatização de plantas micropropagadas do porta-enxerto de macieira Marubakaido. Ciência e Agrotecnologia, Lavras, v. 25, n.2, p. 462-467, 2001.

MACEDO, C.E.C. et al. Concentrações de ANA e BAP na micropropagação de abacaxizeiro L. Merriel (Ananas comosus) e no cultivo hidropônico das plântulas obtidas in vitro. Revista Brasileira de Fruticultura, v.25, p.50104, 2003

MACIEL, M.A.M.; PINTO, A.C.; VEIGA JR. V.F.; GRYNBERG, N.F.; ECHEVARRIA, A. Plantas medicinais: a necessidade de estudos multidisciplinares. Química Nova, v.25, n. 3, p.429-438, 2002.

MANTOVANI, N.C.; FRANCO, E.T.H.; VESTENA, S. Regeneração in vitro de louro-pardo (Cordia trichotoma (Vellozo) Arrabida ex Steudel). Ciência Florestal, v.11, n.2, p.93-101, 2001.

MURASHIGE, T.; SKOOG, F. A revised medium for rapid growth and bio assays with tobacco tissue cultures. Physiologia Plantarum, v.15, n.3, p.473-97, 1962.

NAKAGAWA, J. Testes de vigor baseados no crescimento de plântulas. In: VIEIRA, R.D.; CARVALHO, N.M. Testes de vigor em sementes. Jaboticabal: FUNEP, 1994. p.49-85.

POZO, J.C.D. Hormonal control of the plant cell cycle. Biologia Plantarum, v.123, p.173-83, 2005.

RAO, S.; RAVISHANKAR, G.A. Plant cell cultures: chemical factories of secondary metabolites. Biotecnology Advances, v.20, p.101-153, 2002

REBOUÇAS, F.S. Cultivo in vitro de Plantas Medicinais: Ocimum basilium L. e Cissus sycyoides L. 2009. 61p. Dissertação (Mestrado - Área de Fitotecnia) - Programa de Pós-graduação em Ciências Agrárias, Universidade Federal do Recôncavo da Bahia, Cruz das Almas, Bahia.

ROHR, R.; HANUS, D. Vegetative propagation of wavy grain sycamore maple. Canadian Journal of Forestry Research, v.17, n.5, p.418-20, 1987.

SILVA, A.B. Multiplicação in vitro e aclimatização de gloxínia (Sinningia speciosa Lodd. Hiern.). Lavras: UFLA, 2001. 59p.

TAVANO, E.C. Conteúdos de compostos fenólicos e flavonóides em plantas de camomila (Matricaria recutita 
L. Asteraceae) cultivadas in vivo e in vitro. Naturalia, v.32, p.67-77, 2009.

TOMAZZONI, M. I.; BONATO, R.B.N.; CENTA, M.L.Fitoterapia popular: a busca instrumental enquanto prática terapêutica. Texto Contexto Enferm, v. 15, n.1, p.115-121, 2006.

VEIGA JUNIOR, V.F.; Pinto, A.C.; MACIEL, M.A.M. PLANTAS MEDICINAIS: CURA SEGURA?. Quim. Nova, v. 28, n.3, p.519-528, 2005.
WENDLING, I.; DUTRA, L. F. Produção de mudas de eucalipto por estaquia e miniestaquia. In: WENDLING, I.; DUTRA, L. F. (Eds.). Produção de mudas de eucalipto. Colombo: Embrapa Florestas, 2010. p.50-80.

ZAERR, J.B.; MAPES, M.O. Action of growth regulators. In: BONGA, J.M.; DURZAN, D.J. (Eds). Tissue culture in forestry. Dordrech: Martinus Nijhoff, 1985. p.231-255.

ZAR, J.H. Bioestatistical Analysis. 4.ed. New Jersey: Prentice Hall, 1999. 663p. 